\title{
ALBEDO RETRIEVING FROM DSCOVR/EPIC DATA AND PRELIMINARY VALIDATION
}

\author{
Qiuyue Tian ${ }^{1,2}$, Qiang Liu ${ }^{3}$, Hanwei Zhang ${ }^{1}$, Yahui Che ${ }^{2,4}$, Yanan Wen ${ }^{2,4}$, Zheng Shi ${ }^{2,4}$, Jie Guang ${ }^{2, *}$ \\ ${ }^{1}$ School of Surveying and Land Information Engineering, Henan Polytechnic University, Jiaozuo 454000, China - \\ tianqiuyuew@163.com, hwzhang@hpu.edu.cn \\ ${ }^{2}$ State Environmental Protection Key Laboratory of Satellite Remote Sensing, Institute of Remote Sensing and Digital Earth, \\ Chinese Academy of Science, Beijing 100101, China - guangjie@ casair.ac.cn \\ ${ }^{3}$ College of Global Change and Earth System Science, Beijing Normal University, Beijing 100101, China - toliuqiang@bnu.edu.cn \\ ${ }^{4}$ University of Chinese Academy of Sciences, Beijing 100049, China - (15011546747, m15611670108, sdustchsz)@ 163.com
}

\section{Commission III, WG III/8}

KEY WORDS: Albedo, DSCOVR, EPIC, GLASS, MAIAC, BRDF

\begin{abstract}
:
Land surface albedo plays an important role in climate change research. Satellite remote sensing has the characteristic of wide observation range, and it can make repeated observations on the same area. Therefore, using the remote sensing data to retrieve surface albedo becomes a main method to obtain the surface albedo in a wide range or even on a global scale. However, the time resolution of existing albedo products is usually low, which has a great impact on the analysis of rapid changes in surface vegetation and the climate change research. The Deep Space Climate Observatory (DSCOVR) was launched to a sun-earth first Lagrange point (L1) orbit, which is a new and unique vantage point to observe the continuously full, sunlit disk of Earth. DSCOVR can provide observation data with high time resolution, therefore, it is necessary to explore the feasibility of the new sensor DSCOVR/EPIC inversion of the daily albedo product. The relationship between the surface broadband albedo and the surface reflectance was established, and then the surface albedo with high temporal resolution was calculated using the DSCOVR/EPIC data. The Inner Mongolia Autonomous Region and parts of the Sahara Desert were selected to verify the accuracy of DSCOVR albedo compared with MODIS albedo. The results show that the correlation coefficients between DSCOVR albedo and MODIS albedo are greater than 0.7 and RMSE are less than 0.05 both in visible band and shortwave band. It can be seen that this method can be used for the albedo retrieval using DSCOVR/EPIC data.
\end{abstract}

\section{INTRODUCTION}

Land surface albedo, which is defined as the ratio of the reflected radiation to total incident radiation, is a key parameter controlling the regional and global radiation energy budget (Dickinson, 1983; Manalo-Smith et al., 1998). The change of the surface albedo in time and space is affected by both natural processes and human activities, and it's an indicator of the change of global environmental (Dickinson, 1995).

There are two traditional ways to obtain surface albedo including ground-based observation and satellite remote sensing retrieval. Ground-based observations can obtain surface albedo with high spatial and temporal resolution, but the distribution of such observations is uneven and the spatial representation is small. Therefore, the albedo of ground-based observations is often used to validate the accuracy of the retrieval results (Wang et al., 2010; Liu et al., 2013; Qu et al., 2014).

Due to the extensive coverage of remote sensing, satellite remote sensing has become a major method of obtaining surface albedo over a wide range or even on a global scale. Albedo products are now routinely derived from sensors on polar orbiting satellites such as MODerate resolution Imaging Spectroradiometer (MODIS) (Schaaf et al. 2002), Polarization and Directionality of the Earth's Reflectances (POLDER)
(Leroy et al., 1997), Medium Resolution Imaging Spectrometer (MERIS) (Muller et al., 2008), Multi-angle Imaging SpectroRadiometer (MISR) (Martonchik et al., 1998), the Clouds and the Earth's Radiant Energy System (CERES) (Rutan et al., 2006), Advanced Along-Track Scanning Radiometer (AATSR) (Grey et al., 2006; Kokhanovsky and Roujean, 2009) and from geostationary satellites such as Meteosat (Pinty et al., 2000; Govaerts et al., 2006) and Meteosat Second Generation (MSG) (Leeuwen and Roujean, 2002; Garrer et al., 2016).

Surface albedo has a wide range of applications. In recent years, many studies have applied MODIS surface albedo products to vegetation monitoring (He et al., 2012; Hill et al, 2011), surface classification (Jiao et al., 2011), Surface ice sheet monitoring (Hall et al., 2009), and monitoring of the dynamic change of land surface (Wang et al., 2018). Surface albedo also has important applications in surface snowmelt changes (Wang et al., 2018) and analysis of urban heat island effects ( $\mathrm{Li}$ et al, 2012). Many researchers have used existing surface albedo products to analyse the temporal and spatial distribution of surface albedo and the quality of albedo products in specific regions ( $\mathrm{Li}$ and $\mathrm{Hu}, 2006$; Chen et al., 2018).

Global surface albedos with an absolute accuracy of 0.02-0.05 and a time resolution of daily or monthly (including snow-free and snow-covered land) are required by climate biogeochemical,

\footnotetext{
* Corresponding author
} 
hydrological, and weather forecast models (Henderson and Wilson, 1983; Román et al., 2010). A relative accuracy of 5\%, a horizontal resolution of $1 \mathrm{~km}$, a daily observing cycle, and a stability of $1 \%$ are targets of albedo as in WMO/CEOS database (Mason and Bojinski, 2006). However, the present albedo products retrieved by satellite data cannot reach this requirement. For example, the most widely used MODIS daily surface albedo products are also calculated from multi-day datasets.

The Deep Space Climate Observatory (DSCOVR) was launched on 11 February 2015 to a sun-Earth first Lagrange point (L1) orbit, approximately 1.5 million $\mathrm{km}$ from Earth toward the sun (Marshak et al., 2018). The Earth Polychromatic Imaging Camera (EPIC) which operated on DSCOVR is an imager that provides global spectral images of the entire sunlit face of Earth. It can provide global spectral images of the entire sunlit face of Earth with a high time resolution.

Therefore, in this study, the feasibility of using DSCOVR/EPIC data to retrieve high temporal resolution surface albedo was verified. The relationship between the surface broadband albedo and the surface reflectance was established similar to the retrieval method of GLASS surface albedo (Liu et al., 2013; Qu et al., 2014), and then the surface albedo was calculated with high temporal resolution based on the surface reflectance of DSCOVR/EPIC. Finally, two research areas were selected to validate the accuracy of the albedo retrieval results.

\section{DATA AND METHOD}

\subsection{DSCOVR/EPIC Data}

EPIC onboard DSCOVR is a 10-channel spectroradiometer that uses a cassegrain type telescope. It images the irradiance from the sunlit face of Earth on a $2048 \times 2048$ pixel charge-coupled device (CCD) in 10 narrowband channels from $317.5 \mathrm{~nm}$ to $779.5 \mathrm{~nm}$ (Marshak et al., 2018). Due to the special orbital position of the DSCOVR, it has unique observational advantages including wide coverage, high temporal resolution and unique observation angle. It can produce up to 8-12 images of the same area from dawn to dusk, globally (Marshak et al., 2018). The satellite scattering angle of DSCOVR is between $165^{\circ}-178^{\circ}$, and the relevant data at hot spot can be observed. Therefore, the unique observation advantages of DSCOVR/EPIC offer the possibility of high temporal resolution and global coverage albedo research.

The Level 2 Multi-Angle Implementation of Atmospheric Correction (MAIAC) product contains atmospherically corrected spectral bidirectional reflectance factors (surface reflectance). It can be used to retrieve surface albedo with high temporal resolution, which can be downloaded from NASA website of https://eosweb.larc.nasa.gov/project/dscovr/dscovr_table.

\subsection{Method}

Direct-estimation algorithm is an empirical method to estimating broadband land surface albedo based on the BRDF database (Liang and Member, 2003). It can be used to estimate surface albedo directly from surface directional reflectance. GLASS surface albedo is a typical representative of the albedo calculated by direct inversion method. Therefore, in our study, the surface broad-band albedo was calculated directly with DSCOVR/EPIC surface reflectance using a direct inversion method similar to GLASS surface albedo.
Firstly, the multi-variate linear regression relationship is assumed between the surface broadband albedo and the surface reflectance in the DSCOVR/EPIC visible and infrared spectral bands. The linear relation can be expressed by equation (1):

$$
A=C_{0}\left(\theta_{i}, \theta_{r}, \phi\right)+\sum_{i=1}^{n} C_{i}\left(\theta_{i}, \theta_{r}, \phi\right) \rho_{i}\left(\theta_{i}, \theta_{r}, \phi\right)
$$

where $A=$ the surface broadband white-sky albedo (WSA) or black-sky albedo (BSA) at a certain solar zenith angle

$C_{i}=$ the regression coefficients

$\rho_{i}=$ the surface reflectance in band $i$

$\theta_{i}=$ the solar zenith angle

$\theta_{r}=$ the sensor zenith angle

$\varphi=$ the relative angle between sensor and solar

In order to better describe the directional reflection properties of the surface, the incident and view hemisphere were divided into many angular bins, and then the linear regression model between the narrowband directional reflectance and broadband albedo was established at each angular bin (Liu et al., 2013; Qu et al., 2014). The regression coefficients of each angular bin are obtained using training dataset, which should contain the multiband bidirectional reflectance and the broadband albedo. Similar to the method used in GLASS albedo (Liu et al., 2013; Qu et al., 2014). A training dataset that presents various global surface was built based on the POLDER-BRDF dataset.

POLDER is a sensor onboard the PARASOL satellite with a spatial resolution of $6 \mathrm{~km} \times 7 \mathrm{~km}$ and it acquires the surface reflectance in 9 visible and near infrared wavelengths, including 3 polarization bands (Liang et al., 2014; Zhu et al., 2011). POLDER can observe a target from 16 different view angles, but when the solar zenith angle exceeds $20^{\circ}-60^{\circ}$, the observation angle is very rare, so the POLDER data is needed for interpolation and extrapolation to meet multi-angle data observation (Liang et al., 2014).

Since the coefficients obtained are based on POLDER data (Liang et al., 2014), we need to establish a conversion relationship between POLDER and EPIC sensors, and then the EPIC global daily broadband albedo was generated with EPIC narrowband directional reflectance products.

Due to the influence of cloud coverage and data noise and uncertainties of the inversion algorithm, there are a lot of missing problems with the global black-sky albedo and whitesky albedo in shortwave band and visible band. Hence, it's necessary to fill the data gaps and smooth the global DSCOVR/EPIC albedo. A temporal filtering algorithm as used in post-processing for GLASS albedo product is used in this study. It is assumed that there is a linear relationship between the true albedo $\alpha_{\mathrm{k}}$ on the $k$ th day and the true albedo $\alpha_{\triangle \mathrm{k}+\mathrm{k}}$ on the $(\triangle k+k)$ th day (Qu et al., 2014; Liu et al., 2013). The linear relationship can be expressed by the equation (2):

$$
\alpha_{k}=a_{k} \alpha_{\Delta k+k}+b_{k}+e_{\Delta k}
$$

Where $a_{k}, b_{k}=$ regression coefficients $e_{\Delta k}=$ the random error

In this study, the range of $k$ is from -7 to 8 . MODIS albedo products provide continuous and stable black-sky albedo and 
white-sky albedo in time and space. Hence, the coefficients $a_{k}$, $b k$ were calculated by the priori statistics of MODIS global landsurface albedo.

\section{RESULTS AND DISCUSSIONS}

\subsection{Albedo Result}

The DSCOVR/EPIC global albedo distribution after temporal filtering is shown in Figure 1.

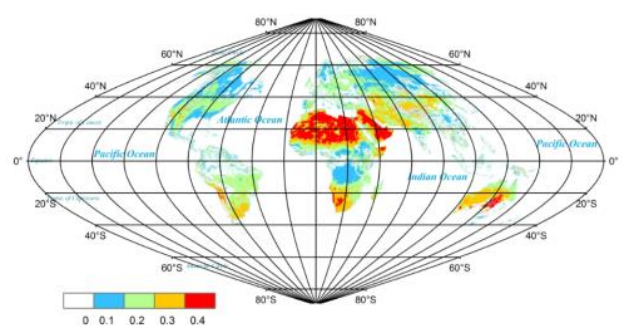

Figure 1. The global distribution of DSCOVR/EPIC short wave black-sky Albedo (BSA) after temporal filtering on $4^{\text {th }}$ June, 2016

\subsection{Albedo Validation}

In order to validate the applicability of the algorithm, some regions of Inner Mongolia Autonomous Region and Sahara Desert were selected as research areas, and the accuracy of the retrieved albedo results was validated.

3.2.1 Inner Mongolia Autonomous Region: Some areas of Inner Mongolia Autonomous Region was selected as research area $\left(115^{\circ}-123^{\circ} \mathrm{E}, 40^{\circ}-48^{\circ} \mathrm{N}\right)$. The study area includes a variety of land types such as vegetation, water bodies, and bare soil, which are conducive to evaluate the applicability of the inversion algorithm.

3.2.2 Sahara Desert: The Gobi and Desert are important underlying types of arid area. It consists mainly of bare soil and has a special response to the sun's radiation. A part of the

Sahara Desert $\left(10^{\circ}-20^{\circ}\right.$ E, $\left.20^{\circ}-30^{\circ} \mathrm{N}\right)$ was selected to verify the inversion accuracy of the DSCOVR albedo in desert.

3.2.3 Compared Data: The MODIS surface albedo product (MCD43A3) is an albedo product produced by the MODLAND team of US which can be downloaded from the relevant website (https://ladsweb.modaps.eosdis.nasa.gov/search/). The MODIS BRDF/Albedo product combines registered, multi-date, multiband, atmospherically corrected surface reflectance data from MODIS and MISR to fit a Bidirectional Reflectance Distribution Function (BRDF) in seven spectral and three broadband (visible band, shortwave band and Near infrared band) bands at a $500 \mathrm{~m}$ spatial resolution on a 16-day cycle (Schaaf et al., 2000), which has validated using ground-based observation. Validation results shows that surface albedo from MCD43 has a high quality (Mira et al. 2013, Feng et al. 2018). In this study, MODIS surface albedo products (MCD43) were used to verify the accuracy of DSCOVR albedo.

We compared the black-sky albedo between DSCOVR/EPIC albedo and MCD43 in the visible band and shortwave band over the two study areas. Due to the inconsistent spatial resolution, the resolution of MODIS was resampled to $10 \mathrm{~km}$.

3.2.4 Validation Results: Figure 2 and Figure 3 are the comparison of DSCOVR/EPIC black-sky albedo (BSA) and MODIS black-sky albedo (BSA) in the visible band and shortwave bands, respectively. In the process of time filtering on DSCOVR/EPIC albedo, there will be a case of filtering failure due to the small number of effective observations (no cloud observations). From the DSCOVR/EPIC albedo distribution map in Inner Mongolia, there is a clear boundary between the lower and upper. The value of the low blue is the value of the filter failure, generally between $0 \sim 0.05$.

It can be seen from Figure 2 and Figure 3 that the distribution of DSCOVR/EPIC black-sky albedo and MODIS black-sky albedo are basically the same in the two study areas. The consistency of DSCOVR/EPIC black-sky albedo and MODIS black-sky albedo is better in the Sahara than in Inner Mongolia both in shortwave band and visible band. In Inner Mongolia, the DSCOVR/EPIC black-sky albedo is higher than the MODIS black-sky albedo, which is more pronounced in visible band. It may be because the elevation changes in Inner Mongolia are obvious, the surface type is more complicated, and the characteristics of surface directional reflectance are greatly affected by the terrain. Therefore, the difference in surface albedo in Inner Mongolia is relatively obvious.
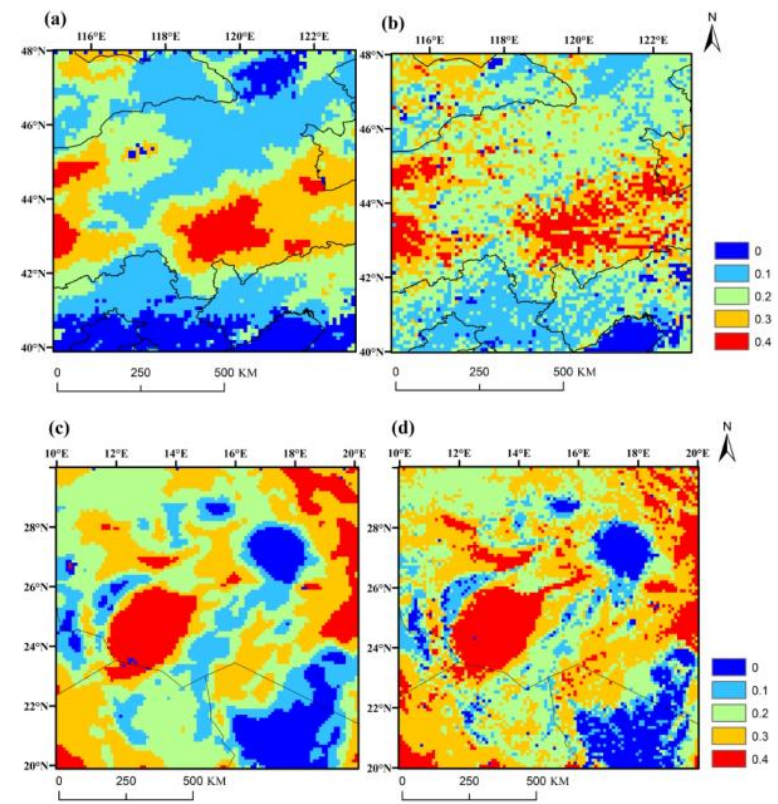

Figure 2. Comparison of black-sky albedo (BSA) in shortwave band, (a) DSCOVR/EPIC albedo in Inner Mongolia, (b) MODIS albedo in Inner Mongolia, (c) DSCOVR/EPIC albedo in Sahara, (d) MODIS albedo in Sahara 

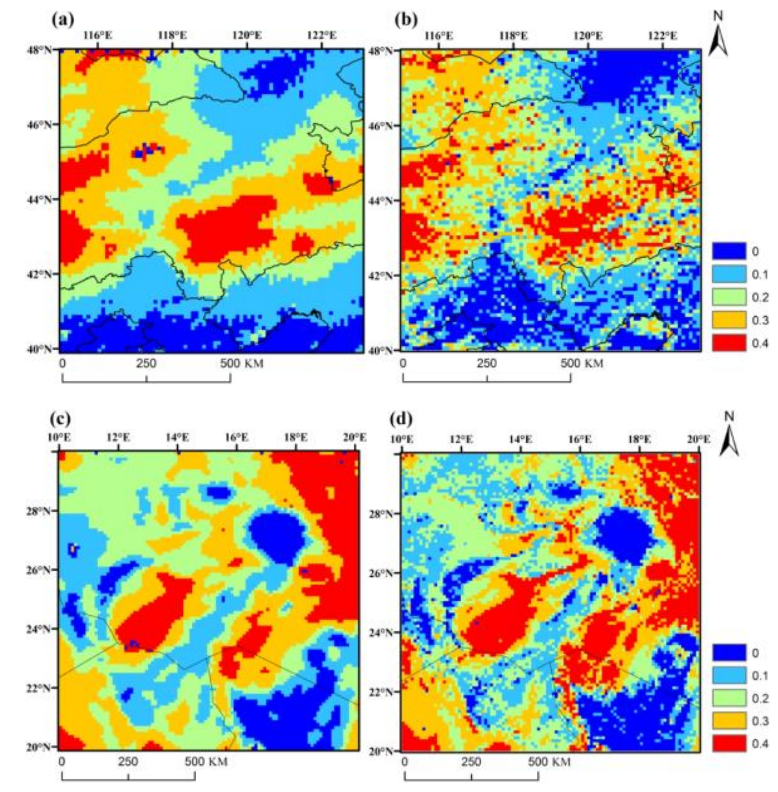

Figure 3. Comparison of black-sky albedo (BSA) in visible

band, (a) DSCOVR/EPIC albedo in Inner Mongolia, (b)

MODIS albedo in Inner Mongolia, (c) DSCOVR/EPIC albedo in Sahara, (d) MODIS albedo in Sahara

In order to further validate the accuracy of the inversion results, the DSCOVR/EPIC albedo of each pixel was matched with the MODIS albedo in the two study areas, and the accuracy of black-sky albedo in visible band and shortwave band was verified. Because the resolution of DSCOVR albedo and MODIS albedo are inconsistent, it is necessary to resample MODIS albedo to $10 \mathrm{~km} \times 10 \mathrm{~km}$.

It can be seen from Figure 4 and Figure 5 that the DSCOVR/EPIC albedo is higher than MODIS albedo overall. This result is consistent with the result of the albedo distribution maps in Figure 2 and Figure 3. That may due to the DSCOVR/EPIC observe the sunlit face of Earth, which is the hot-spot direction. Moreover, the accuracy of DSCOVR/EPIC albedo in the desert region is greater than the albedo in the Inner Mongolia region. It may be because the Inner Mongolia area has a complex surface cover type and a large change in altitude, so the surface albedo accuracy is low in this area.

In Inner Mongolia, the accuracy of DSCOVR/EPIC black-sky albedo in visible band is higher than that of shortwave band black-sky albedo. In the visible band, the correlation coefficient (R) between DSCOVR/EPIC albedo and MODIS albedo is 0.8, and the RMSE is 0.03. In the shortwave band, the correlation coefficient between DSCOVR/EPIC albedo and MODIS albedo is 0.72 , which is slightly lower than the coefficient of the visible band. This difference may be related to the error of coefficient from narrow band to broadband albedo conversion.

In the desert area, the accuracy of the DSCOVR/EPIC albedo in the visible band is consistent with shortwave band, and the correlation coefficient $(\mathrm{R})$ is greater than 0.8 . It indicate that the results of DSCOVR/EPIC albedo and MODIS albedo are consistent. The surface types in desert area is relatively uniform, so the accuracy of the retrieved albedo result is slightly better than that in Inner Mongolia.

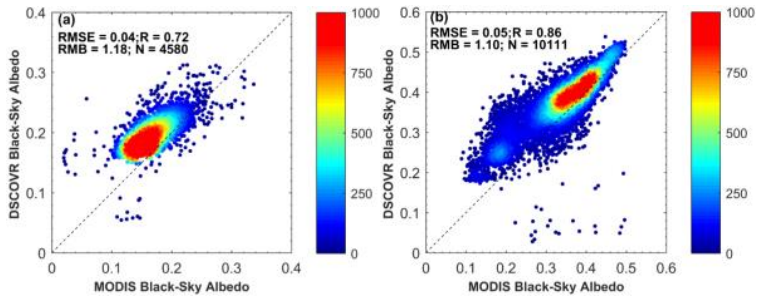

Figure 4. Comparison of black-sky albedo in shortwave band, (a) Inner Mongolia, (b) Sahara. The colour of a point is determined by the density of the position at which the point is located

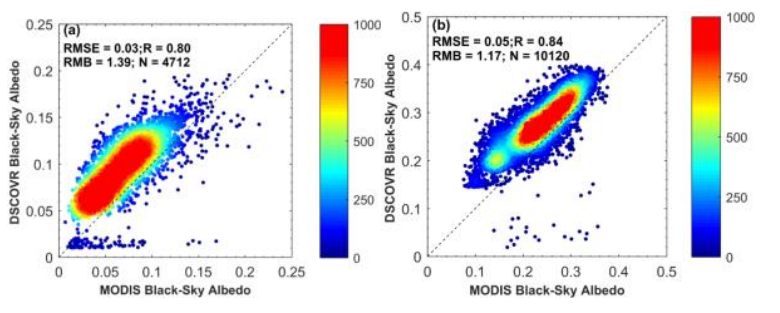

Figure 5. Comparison of black-sky albedo in visible band, (a) Inner Mongolia, (b) Sahara. The colour of a point is determined by the density of the position at which the point is located

\section{CONCLUSIONS}

The Earth Polychromatic Imaging Camera (EPIC) which operated on DSCOVR is an imager that provides global spectral images of the entire sunlit face of Earth at sun-Earth first Lagrange point (L1) orbit. The temporal resolution is about 2 hours. It is possible to obtain a global surface albedo with high temporal resolution.

DSCOVR_EPIC_MAIAC products provide surface reflectance with a resolution of $10 \mathrm{~km}$. Therefore, the direct inversion method was used and a linear relationship between the surface broadband albedo and the surface directional reflectance is established, and then black-sky albedo (BSA) in visible band and shortwave band from DSCOVR/EPIC were calculated.

The DSOCVR/EPIC albedo results are compared with MODIS albedo products (MCD43A3) over different surface types. Overall, the DSCOVR/EPIC albedo is consistent with the MODIS albedo, but there is a slightly higher than the MODIS albedo. These differences may be due to hot-spot observation of DSCOVR/EPIC data. Hence, the method developed in this paper can be used for the albedo retrieval using DSCOVR/EPIC data.

\section{ACKNOWLEDGEMENTS}

This work was supported in part by the National Natural Science Foundation of China (NSFC) under grant nos. 41590855, 41871260 and 41471306, the Ministry of Science and Technology (MOST) of China under grant nos. 2016YFC0200500. We are thankful to the National Aeronautics and Space Administration (NASA) Earth data centre (EOSDIS) for providing access to the DSCOVR/EPIC and MODIS albedo data. 


\section{REFERENCES}

Carrer, D., Roujean, J.L., Hautecoeur, O., Elias, T., 2010. Daily estimates of aerosol optical thickness over land surface based on a directional and temporal analysis of SEVIRI MSG visible observations. J. Geophys. Res. - Atmos., 115(D10). doi.org/ 10.1029/2009JD012272.

Chen, A.J., Zhou, F., Liang, X.W., Lingen, B., Liu, Y.J., 2018. Analysis of the distribution of MODIS albedo inversion in China. Trans. Atmos. Sci., 41(2), 267-274.

Dickinson, R.E., 1983. Land surface processes and climatesurface albedos and energy balance. Adv. Geophys., 98(1), 8095.

Dickinson, R.E., 1995. Land processes in climate models. Remote Sens. Environ., 51(1), 27-38.

Feng, Z.M., Wen, J.G., Xiao, Q., You, D.Q., Lin, X.W., Wu, X.D., 2018. Comparison of global products of MODIS V006 and V005 based on FLUXNET. J. Remote Sens., 22(1), 101113.

Govaerts, Y., Pinty, B., Taberner, M., Lattanzio, A., 2006. Spectral conversion of surface albedo derived from MeteoSat first generation observations. IEEE Geosci. Remote Sens. Lett., $3(1), 23-27$.

Grey, W.M.F., North, P.R.J., Los, S.O., Mitchell, R.M., 2006. Aerosol optical depth and land surface reflectance from multiangle AATSR measurements: global validation and intersensor comparisons. IEEE Trans. Geosci. Remote Sens., 44(8), 2184-2197.

Hall, D.K., Nghiem, S.V., Schaaf, C.B., Digirolamo, N.E., Neumann, G., 2009. Evaluation of surface and near-surface melt characteristics on the Greenland ice sheet using MODIS and QuikSCAT data. J. Geophys. Res.-Atmos, 114 (F4). Doi.org/ 10.1029/2009JF001287.

He, L., Qin, Q.M., Liu, M.C., Dong, H., 2012. Validation of GLASS albedo products using ground measurements and Landsat TM data. In Proceedings of the 2012 IEEE International Geoscience and Remote Sensing Symposium (IGARSS), 1116-1119.

Henderson-Sellers, A., Wilson, M.F., 1983. Surface albedo data for climatic modeling. Rev. Geophys., 21(8), 1743-1778.

Hill, M.J., Román, M.O., Schaaf, C.B., Hutley, L., Brannstrom, C., Etter, A., Hanan, N.P., 2011. Characterizing vegetation cover in global savannas with an annual foliage clumping index derived from the MODIS BRDF product. Remote Sens. Environ., 115(8), 2008-2024.

Jiao, Z.T., Woodcock, C., Schaaf, C.B., Tan, B., Liu, J.C., Gao, F., Strahler, A., Li, X.W., Wang, J.D., 2011. Improving MODIS land cover classification by combining MODIS spectral and angular signatures in a Canadian boreal forest. Can. J. Remote Sens., 37(2), 184-203.

Kokhanovsky, A., Schreier, M., 2009. The determination of snow specific surface area, albedo and effective grain size using
AATSR space-borne measurements. Int. J. Remote Sens., 30(4), 919-933.

Leroy, M.M., Deuzé, J.L., Bréon, F.M., Hautecoeur, O., Herman, M., Buriez, J.C., Tanré, D., Bouffiès, S., Chazette, P., Roujean, J.L., 1997. Retrieval of atmospheric properties and surface bidirectional reflectances over land from POLDER/ADEOS. J. Geophys. Res., 102, 17023-17038.

Li, Y., Hu, Z.Y., 2006. A preliminary study on land-surface albedo in Northern Tibetan Plateau. Pla. Meteorol., 25(6), 1034-1041.

Li, Y.H., Shen, S.H., Zhao, X.Y., 2012. Application of MODIS albedo data in the simulation of air temperature over Beijing. $J$. Meteorol. Sci., 32(6), 622-628.

Liang, S.L., Member, S., 2003. A direct algorithm for estimating land surface broadband albedos from MODIS imagery. IEEE Trans. Geosci. Remote Sens., 41(1), 136-145.

Liang, S.L., Zhang, X.T., Xiao, Z.Q., Cheng, J., Liu, Q., Zhao, X., 2014. Shortwave Albedo. Global land surface satellite (GLASS) products. Springer International Publishing.

Liu, N.F., Liu, Q., Wang, L.Z., Liang, S.L., Wen, J.G., Qu, Y., Liu, S.H., 2013. A statistics-based temporal filter algorithm to map spatiotemporally continuous shortwave albedo from MODIS data. Hydrol. Earth Syst. Sci, 17(6), 2121-2129.

Liu, Q., Wang, L.Z., Qu, Y., Liu, N.F., Liu, S.H, Tang, H.R., Liang, S.L., 2013. Preliminary evaluation of the long-term GLASS albedo product. Int. J. Digit. Earth, 6(sup1), 69-95.

Manalo-Smith, N., Smith, G.L., Tiwari, S.N., Staylor, W.F., 1998. Analytic forms of bidirectional reflectance functions for application to earth budget studies. Geophys. Res. 103, 1973319751.

Marshak, A., Herman, J., Adam, S., Karin, B., Carn, S., Cede, A., Geogdzhyev, L., Huang, D., Huang, L. K., Knyazikhin, Y., Kowalewski, M., Krotkov, N., Lyapustin, A., Mcpeters, R., Meyer, K.G., Torres, O., Yang, Y. K., 2018. Earth observations from DSCOVR EPIC instrument. Bull. Amer. Meteorol. Soc, 99(9), 1829-1850.

Martonchik, J.V., Diner, D.J., Pinty, B., Verstraete, M.M., Gordon, H.R., 1998. Determination of land and ocean reflective, radiative, and biophysical properties using multi-angle imaging. IEEE Trans. Geosci. Remote Sens., 36(4), 1266-1281.

Mason, P., Bojinski, S., 2006. Systematic observation requirements for satellite-based products for climate: Supplemental details to the satellite-based component of the implementation plan for the global observing system for climate in support of the UNFCCC. Technical Report GCOS-107, WMO/TD No. 1338 World Meteorological Organization.

Mira, M., Courault, D., Olioso, A., Weiss, M., Marloie, O., Baret, F., Hagolle, O., Gallego-Elvira, B., 2013. Validation of MODIS albedo products with high resolution albedo estimates from FORMOSAT-2. In Proceedings of the 2013 IEEE International Geoscience and Remote Sensing Symposium (IGARSS), 3250-3253. 
Muller, J.P., Zuhlke, M., Brockmann, C., Preusker, R., Fischer, J., Regner, P., 2007. ALBEDOMAP: MERIS land surface albedo retrieval using data fusion with MODIS BRDF and its validation using contemporaneous EO and in situ data products. In 2007 IEEE International Geoscience and Remote Sensing Symposium, 2404-2407.

Pinty, B., Roveda, F., Verstraete, M.M., Gobron, N., Govaerts, Y., Martonchik, J.V., Diner, D. J., Kahn, R., 2000. Surface albedo retrieval from Meteosat: 1. theory. J. Geophys. Res. Atmos., 105(D14), 18099. Doi.org/ 10.1029/2000jd900113.

Qu, Y., Liu, Q., Liang, S.L., Wang, L.Z., Liu, N.F., Liu, S.H., 2014. Direct-estimation algorithm for mapping daily landsurface broadband albedo from MODIS data. IEEE Trans. Geosci. Remote Sens., 52(2), 907-919.

Román, M.O., Schaaf, C.B., Lewis, P., Gao, F., Anderson, G.P., Privette, J.L., Strahler, A.H., Woodcock, C.E., Barnsley, M., 2010. Assessing the coupling between surface albedo derived from MODIS and the fraction of diffuse skylight over spatiallycharacterized landscapes. Remote Sens. Environ., 114(4), 738760 .

Rutan, D., Charlock, T., Rose, F.S., Kato, S., Zentz, S., Coleman, L., 2006. Global surface albedo from CERES/TERRA surface and atmospheric radiation budget (SARB) data product. Proceedings of 12th Conference on Atmospheric Radiation (AMS), Madison, Wisconsin, 10-14 July 2006.

Schaaf, C.B., Gao, F., Strahler, A.H., Lucht, W., Li, X., Tsang, T., Strugnell, N.C., Zhang, X.Y., Jin, Y.F., Muller, J.P., Lewis, P., Barnsley, M., Hobson, P., Disney, M., Robert, G., Dunderdale, M., Doll, C., d'Entremont, R.P., Hu, B.X., Liang, S.L., Privette, J.L., Roy, D., 2002. First operational BRDF, albedo nadir reflectance products from MODIS. Remote Sens. Environ., 83(1-2), 135-148.

Schaaf, C.B., Feng, G., Strahler, A.H., Tsang, T., Lucht, W., Strugnell, N., Li, X.W., Muller, J.P., Lewis, P., Barnsley, M., Hobson, P., Disney, M., Dunderdale, M., Robert, S.G., 2000. Initial results from the moderate resolution imaging spectroradiometer (MODIS) BRDF and albedo product. In 2000 IEEE International Geoscience and Remote Sensing Symposium, 1506-1508.

van Leeuwen, W.J.D., Roujean, J.L., 2002. Land surface albedo from the synergistic use of polar (EPS) and geo-stationary (MSG) observing systems: an assessment of physical uncertainties. Remote Sens. Environ., 81(2-3), 273-289.

Wang, K.C., Liang, S.L., Schaaf, C.L., Strahler, A.H., 2010. Evaluation of moderate resolution imaging spectroradiometer land surface visible and shortwave albedo products at FLUXNET sites. J. Geophys. Res.-Atmos, 115(D17). Doi.org/ 10.1029/2009JD013101.

Wang, Z.S., Schaaf, C.B., Sun, Q.S., Shuai, Y.M., Román, M. O., 2018. Capturing rapid land surface dynamics with collection V006 NODIS BRDF/NBAR/Albedo (MCD43) products. Remote Sens. Environ, 207, 50-64.

Zhu, G.L., Ju, W.M., Chen, J.M., Liu, Y.B., Zhu, J.F., Xing, B.L., 2011. Validation of MODIS BRDF model parameters product and the Ross-Li model with polder data. J. Remote Sens., 15(5), 875-894. 